\title{
Bio-demographic factors affecting child loss in Tanzania
}

\author{
A. Sathiya Susuman ${ }^{*}$, Hamisi F. Hamisi ${ }^{2}$ and R. Nagarajan ${ }^{3}$
}

\author{
* Correspondence: \\ sappunni@uwc.ac.za \\ ${ }^{1}$ Department of Statistics and \\ Population Studies, University of the \\ Western Cape, Bellville, Cape Town \\ 7535, South Africa \\ Full list of author information is \\ available at the end of the article
}

\begin{abstract}
The Republic of Tanzania has been experiencing one of the highest infant and child mortality rates. There have been few efforts in understanding the bio-demographic factors associated with child loss. The 2011-2012 Tanzania HIV/AIDS and Malaria Indicator Survey is the third comprehensive survey on HIV/AIDS carried out in Tanzania. This study employed logistic regression ratios to estimate the effects of key bio-demographic variables on the outcome variable (child loss). Children who belonged to mothers with parity 4 to 8 and more than 9 had 1.27 and 1.08 times more risk of dying, respectively, compared to children in parity less than 3 . Birth interval is one of the most important key factors to reduce child mortality. A birth spacing of 24 months or longer was observed in the successive birth interval of $76 \%$ of the respondents. Special health care service fund allocation is essential to reduce child mortality in Tanzania. There is no doubt that the funding from international donor agencies and global partnerships will be important to the country's progress toward reducing infant, child, and maternal mortality.

Keywords: Infant mortality, Child mortality, Maternal mortality, Birth spacing, Birth interval
\end{abstract}

\section{Background}

Bio-demography is an interdisciplinary approach to demography in which biological considerations (e.g., genetic, epidemiological, and evolutionary determinants) are emphasized: the study of the influence of biological factors on demographic patterns (e.g., relating to fertility, mortality, health, aging, and longevity) of human populations or populations of other sexually reproducing species (Gavrilov and Gavrilova 2012).

There are different approaches to study infant and child mortality depending on the discipline of the study undertaken. In demography, for example, the study of child mortality is linked with socioeconomic and demographic determinants that influence the survival and health of children. Economists look at the association between household's assets and wealth and child mortality, whereas epidemiologists and medical professionals concentrate mainly on the diseases and malnutrition that cause child mortality (Claeson et al. 2000).

A number of studies have addressed factors that plausibly contributed to child mortality in Tanzania. First, a brief account of the factors associated with infant and child mortality (Sathiya Susuman 2010; Trussell 1975) pointed out that many countries have endorsed Millennium Development Goal number four (MDG4), with its aim to reduce

(c) 2016 The Author(s). Open Access This article is distributed under the terms of the Creative Commons Attribution 4.0 International License (http://creativecommons.org/licenses/by/4.0/), which permits unrestricted use, distribution, and reproduction in any medium, provided you give appropriate credit to the original author(s) and the source, provide a link to the Creative Commons license, and indicate if changes were made. 
infant and child mortality by two thirds (between 1990 and 2015). Estimates of infant and child mortality are not available for Tanzania for earlier decades as the statistical or vital registration system had not functioned well (Stanley 2010). However, it is generally accepted that child mortality in Tanzania has been high in the past. But indirect estimates by bio-demographic variables have been pointed to by several authors, which shows that they are the most important variables as they are the ones through which socioeconomic factors have to operate to exert an impact on child health (Sathiya Susuman 2010; Stanley 2010; Nattey 2008). The concept of bio-demographic variables in literature embraces maternal fertility behavior (biological factor), number of children ever born (CEB), and sex of the head of the household (Nattey 2008; Nure Alam et al. 2011). Teenage pregnancies are associated with physical immaturity, birth complications, and delivering a baby with a low birth weight. Pregnancies at older reproductive ages result in pregnancy complications. All these translate into a high risk of death among newly born babies (Nattey 2008; Kembo and Van Ginneken 2009; Nure Alam et al. 2011; Charmarbagwala et al. 2004). Similarly, a U-shaped relationship between the age of the mother and child mortality has been established by some scholars (Shipanga 2007). A Namibian study shows that this relationship means that more children are dying whose mothers are less than 23 and 40 to 49 years old (Ahmad et al. 2000). On the contrary, however, it identifies that the high risk of dying among infants and children is found in mothers of older ages, specifically 35 years old and above (Hossain and Islam 2009). But it should be borne in mind that these authors did not control for other variables like birth interval or parity in their analysis. The consensus has however been reached that raising the age at giving birth to about 25 years old and stopping reproductive activities at age 34, as suggested by researchers (Sathiya Susuman 2010), reduces child mortality indirectly through lowering the fertility level (reducing birth parity). Birth interval is the period between a child's birth and succeeding and/or previous sibling births (Nure Alam et al. 2011), and it influences child mortality in a number of ways (Rutstein 2005). A short birth interval means that (i) children have a short time for breast-feeding, (ii) mothers' time to restore nutrients becomes insufficient and they probably will continue to give birth to unhealthy children, and (iii) increase the total fertility, which results in resource competition among siblings (Nure Alam et al. 2011; Hossain and Islam 2009; Rutstein 2005; Ojikutu 2008).

A short preceding birth interval is strongly correlated with a high infant mortality rate (IMR), whereas a short subsequent birth interval is associated with a high child mortality rate (Rutstein 2005; Landau and Everitt 2004). Studies have found that between 24 and 36 months or more are ideal intervals and children born with these intervals have better survival chances than those born with less than 24 months of a birth interval. Mortality among under-five children is disproportionately higher among highrisk groups, such as infant of multiple births (UNDP 2010; Tanzania Millennium Development Goals 2010; MoHSW 2008). In this light, multiple births are complicated with high risks of diseases and pregnancy complications; furthermore, children of multiple births are thought to suffer a high risk of malnutrition. Likewise, researchers (Sathiya Susuman 2010; Whiting et al. 2006) found that multiple births are always related to high child mortality rates, specifically neonate mortality, because of complications during delivery and most of multiple births are delivered with low birth weight. Thus, higher under-five mortality is experienced with children of multiple births than those 
of singleton (Nure Alam et al. 2011; Morris et al. 2003; Janson 2007). The order of children with respect to a sibling has an impact on child mortality. It has been set in the theory that high mortality is found in the first order (first born) and to children of high orders. Different studies (Sathiya Susuman 2010; Nure Alam et al. 2011; Kembo and Van Ginneken 2009; Armstrong Schellenberg et al. 2000; Tanzania Demographic Health Survey 2004-2005; MoHSW 2006; Handa et al. 2010) have found an association between high child mortality and children of first and higher orders. Many studies mention that the health of the children depends on the delivery of services by the government, nongovernmental organizations (NGOs), private sectors, traditional services, and illegal providers (Stanley 2010; Rutstein 2005; Ojikutu 2008; Masanja et al. 2008; Claeson et al. 2000). Similarly, using the updated model of Mosley-Chen (Gavrilov and Gavrilova 2012), the World Bank Poverty Reduction Strategy Paper Sourcebook explains that the health outcomes of children and their overall survival chances are influenced by service delivery in the health sectors and other sectors like water, energy, and sanitation (Landau and Everitt 2004; UNDP 2010; Tanzania Millennium Development Goals 2010). Regardless of these service deliveries, the questions still remain as to what extent the households can access these services. Thus, it has been postulated that the accessibility of services by households is in turn influenced by their socioeconomic status. Related studies (Claeson and Waldman 2000; World Health Organization 2010; Buwembo 2010; Pathak and Ram 1998; Trussell 1975) show that unsafe drinking water possibly affects child mortality as it carries vectors that cause diseases like diarrhea, cholera, dysentery, and typhoid.

This study is based on the four essential conditions for child mortality specified by Mosley-Chen 1984. Using the Tanzania HIV/AIDS and Malaria Indicator Survey (2011-2012) data, the study strives to estimate child mortality and studying the determinants of child loss in relation to some selected socioeconomic, bio-demographic, maternal fertility, and service delivery variables. Therefore, the purpose of the study is to investigate how the specific bio-demographic factors are associated with infant and child mortality in Tanzania and tries to test the following alternative hypothesis (H1): Child mortality rate is independent of all predictors of deaths. This article therefore focuses on selected bio-demographic issues that make an effort to see if a general clarification was raised.

\section{Data and methods \\ Data}

The study used weighted large-scale data from the 2011-2012 Tanzania HIV/AIDS and Malaria Indicator Survey, which is the third comprehensive survey on HIV/AIDS. A nationally representative sample of 10,967 women age 15 to 49 and 8,352 men age 15 to 49 were interviewed. This represents a response rate of $96 \%$ for women and $89 \%$ for men. About one quarter of households was headed by women. Almost half of the population is under the age of 15 . The variables for this analysis were selected from three different files, namely child birth history, household particulars, and women's file. The reference period for child birth was considered up to 5 years preceding the survey. The statistical significance level was set at $P<0.005$.

The coverage of key interventions relevant to infant and child survival improved from the 2005 to 2012 data sets (Fig. 1). All the indicators have shown noticeable changes, but the health institutional delivery $(<60 \%)$ and birth interval less than 24 months 


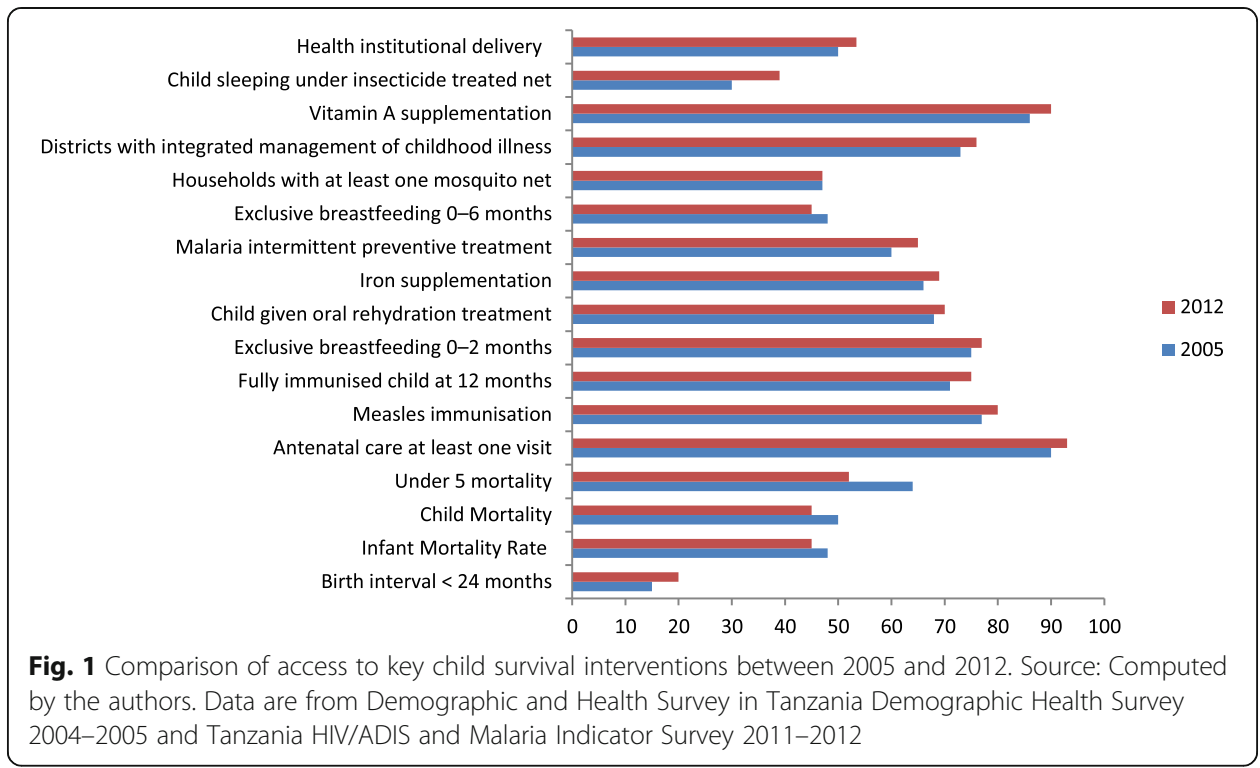

remained very low and therefore unlikely to have contributed to any reduction in infant and child mortality. In addition to that, a theoretical framework, developed by MosleyChen 1984, was included.

\section{Statistical analysis}

The SPSS version 23 was used to estimate the odds of child mortality (child loss) with the variables in the theoretical framework through the use of odds ratios with single and multiple predictors. Using a multivariate analysis in the form of logistic regression of child mortality (child loss) by single predictors in the framework, the study calculated the odds of child mortality with all the predictors in the framework at once (Trussell 1975). The outcome-dependent variable was coded as (mother experienced loss of child $=1$ ) if the child died between the ages of 0 and 4 years, 11 months, and 30 days (i.e., under 5 years); otherwise, we coded 0 . The outcome variable includes neonatal, post neonatal, infant, child and under 5 mortality. This provides clarity and increases the visibility of each characteristic presented separately. We present here the purpose of detection of the specific causes of diseases that affect child mortality in Tanzania. The presentation starts with socioeconomic characteristics in the model (model 1), then adds maternal fertility behavior into the model (model 2), followed by demographic characteristics (model 3) and, last, health care services (model 4). Odds values were used to check the significant contribution of each predictor in the model. If the coefficient is significantly different from 0 , then the predictor is making a statistically important contribution to the outcome.

Child mortality in Tanzania calculated by Trussel equation The probability of dying at early ages was estimated indirectly using data on the average number of children ever born (CEBi) and average number of children surviving (CSi) tabulated by mothers in the reproductive age using MORTPAK. This procedure enabled the indirect estimation of child mortality (4q1) and life expectancy at birth that relate to each $q x$ value 
within each model life-table (MLT) pattern. The Brass (1968) method for converting proportion dead (Di) of the CEBi reported by women age 15 to 49 years into an estimator of the probability of dying $(q x)$ before attaining a certain exact childhood age by using north MLT was adopted. More detailed information on this proposed method is well explained (Pathak and Ram 1998; Trussell 1975). Finally, omnibus tests for model coefficients and Hosmer-Lemeshow (H-L) goodness of fit tests for model evaluation were also done in Tanzania from 2011 to 2012.

\section{Results}

The results of odds ratios of multiple predictors were used for the purpose of detection of the specific causes of factors that affect child mortality in Tanzania. In theory, health, water, sanitation, and energy are mentioned as influencing child health outcomes (World Health Organization 2010). It is however worth mentioning that household behaviors and wealth play major roles in making sure that these households access the required services for the survival of their children.

Table 1 presents the odds of child death by maternal fertility behavior. Age of the mothers' overall statistics was significant; the older the mother, the more likely the child would die. But when looking at the age at first birth, we found that as the age at first birth increases, the chance of dying drops by approximately $1 \%$. The birth intervals between siblings were also found significant. Children born with the preceding intervals of more than 49 months had 0.9 odds of dying ( 1.3 times more likely to survive) compared to those with a preceding interval of less than 24 months. There was no much difference within the remaining intervals. On the other side, succeeding intervals showed

Table 1 Odds ratios of child mortality (loss/death) by socioeconomic characteristics in Tanzania, 2011-2015

\begin{tabular}{|c|c|c|c|}
\hline \multirow[t]{2}{*}{ Variables } & \multirow[t]{2}{*}{$\operatorname{Exp} \beta$} & \multicolumn{2}{|c|}{$95 \% \mathrm{Cl}$ for $\exp \beta$} \\
\hline & & Lower & Upper \\
\hline \multicolumn{4}{|c|}{ Place of residence (ref: urban) } \\
\hline Rural & 1.2 & 0.9 & 1.4 \\
\hline \multicolumn{4}{|c|}{ Regions (ref: Dar es Salaam) } \\
\hline Other regions & 1.3 & 0.8 & 1.9 \\
\hline Zanzibar & 1.2 & 0.8 & 1.9 \\
\hline \multicolumn{4}{|c|}{ Wealth index (ref: poorest) } \\
\hline Poor & 1.1 & 0.9 & 1.4 \\
\hline Middle income & 1.1 & 0.9 & 1.3 \\
\hline Rich & 1.1 & 0.9 & 1.3 \\
\hline Richest & 0.8 & 0.6 & 1.0 \\
\hline \multicolumn{4}{|c|}{ Maternal education (ref: no education) } \\
\hline Primary education & 0.9 & 0.8 & 1.1 \\
\hline Higher education & 0.2 & 0.0 & 1.8 \\
\hline \multicolumn{4}{|c|}{ Paternal education (ref: at most primary) } \\
\hline Secondary & 0.9 & 0.6 & 1.4 \\
\hline Higher education & 1.9 & 0.6 & 5.7 \\
\hline \multicolumn{4}{|c|}{ Labor market (ref: not working) } \\
\hline Working & 1.0 & 0.8 & 1.2 \\
\hline
\end{tabular}

Source: computed by the authors 
implausible results. Birth parity was also statistically significant with the odds of child mortality. Children who belonged to mothers with parity 4 to 8 and greater than 9 had 1.3 and 1.1 times more risk of dying, respectively, compared to children in parity less than 3. In multiplicity and frequency of birth, we found that children with one third multiple of births had 1.1 times more risk of dying compared to single births, whereas we observed less difference between the first and second of multiple of births. This prediction was statistically significant. With regard to birth order, we found that the children of order 2 to 3 and greater than 4 had odds of dying 1.4 and 1.3 times more, respectively, compared to children of the first order.

In terms of service delivery, all the variables were statistically significant except the type of toilet facilities, as shown in Table 2. In this category, the risk of dying was 2.0 times higher in households with no toilet facilities compared with children who belonged to households with flush toilets. The sources of drinking water were not significant, but children with sources apart from piped water were 1.0 times more likely to die. On the other side, the main source of energy was also statistically significant. However, children who lived in households that used paraffin had a risk of dying of 1.1

Table 2 Odds ratios of child mortality by maternal fertility behavior in Tanzania 2011-2015

\begin{tabular}{|c|c|c|c|}
\hline \multirow[t]{2}{*}{ Variables } & \multirow[t]{2}{*}{$\operatorname{Exp} \beta$} & \multicolumn{2}{|c|}{$95 \% \mathrm{Cl}$ for $\exp \beta$} \\
\hline & & Lower & Upper \\
\hline \multicolumn{4}{|l|}{ Age group (ref: 15-19) } \\
\hline $20-24$ & 1.6 & 0.5 & 5.8 \\
\hline $25-29$ & 3.9 & 1.2 & 13.1 \\
\hline $30-34$ & 3.6 & 1.1 & 12.21 \\
\hline $35-39$ & 3.3 & 0.9 & 11.2 \\
\hline $40-44$ & 3.3 & 0.9 & 11.1 \\
\hline $45-49$ & 3.9 & 1.2 & 13.2 \\
\hline Age at 1 st birth & 0.9 & 0.9 & 1.0 \\
\hline \multicolumn{4}{|c|}{ Preceding birth interval (ref: <24) } \\
\hline 24-36 months & 1.4 & 1.1 & 1.7 \\
\hline 37-48 months & 1.4 & 1.1 & 1.9 \\
\hline $49+$ months & 0.9 & 0.7 & 1.3 \\
\hline \multicolumn{4}{|c|}{ Succeeding birth interval (ref: <24) } \\
\hline 24-36 months & 2.2 & 1.8 & 2.6 \\
\hline 37-48 months & 2.8 & 2.2 & 3.6 \\
\hline $49+$ months & 2.3 & 1.8 & 2.9 \\
\hline \multicolumn{4}{|l|}{ Birth parity (ref: $\leq 3$ ) } \\
\hline 4-8 children & 1.3 & 1.0 & 1.6 \\
\hline $9+$ children & 1.1 & 0.9 & 1.4 \\
\hline \multicolumn{4}{|c|}{ Multiplicity of birth (ref: single birth) } \\
\hline 1st of multiple & 0.3 & 0.2 & 0.5 \\
\hline 2nd of multiple & 0.5 & 0.3 & 0.7 \\
\hline 3rd of multiple & 1.1 & 0.2 & 6.0 \\
\hline \multicolumn{4}{|l|}{ Birth order (ref: 1st order) } \\
\hline 2nd-3rd order & 1.4 & 1.2 & 1.7 \\
\hline 4th order and higher & 1.3 & 1.0 & 1.5 \\
\hline
\end{tabular}

Source: computed by the authors 
times more than those in households with electricity. It was observed that the risk was lower among children who belonged to households that used firewood. The relationship between distance to health facilities and child mortality was not clear as we found an increase in distance from the health center leading to a drop in mortality by 0.9 .

Starting with Table 3, the presentation shows socioeconomic characteristics in the model (model 1), then an addition of maternal fertility behavior into the model (model 2), followed by bio-demographic characteristics (model 3), and, last, service delivery factors (model 4). The results for odds of child mortality with multiple predictors are presented in the same table. All the variables in the first model, with socioeconomic factors alone, were statistically significant. The wealth index was the major contributor to the odds of child mortality. Birth order was also significant; the odds of surviving were raised to the higher orders, but the rest of maternal fertility behavior was somewhat significant. However, preceding birth interval was the major contributor in the model. When biodemographic variables were introduced into the model, all the predictors with the exception of birth order were statistically significant with positive effects in determining the odds of child mortality. Children belonging to the higher order had odds of dying of 0.2. Still, a preceding birth interval of 24 to 36 months was the major contributor into the model, with statistically negative effects with reference category. Finally, after taking service delivery into account, the age at first birth became significant again with the odds of surviving increase by 1.6 times with an increase in age of the mother at first birth. Birth order and distance to the nearest health facilities also had statistically negative effects, with odds of -2.7 with less than three births. In birth order, children that belonged to the higher order had 0.1 odds of dying, whereas the odds of dying for children were 0.8 times more when their mothers struggled to reach their nearest health facilities.

Table 4 shows that child mortality (4q1) and life expectancy at birth for the 5 years preceding the survey (calendar year May 2003) are 31 per 1000 live births and 63.4 years, respectively. The table further indicates that $4 \mathrm{q} 1$ in the country have been

Table 3 Odds ratios of child mortality by service delivery factors in Tanzania 2011-2015

\begin{tabular}{|c|c|c|c|}
\hline \multirow[t]{2}{*}{ Variables } & \multirow[t]{2}{*}{$\operatorname{Exp} \beta$} & \multicolumn{2}{|c|}{$95 \% \mathrm{Cl}$ for $\exp \beta$} \\
\hline & & Lower & Upper \\
\hline \multicolumn{4}{|c|}{ Drinking water (ref: piped water) } \\
\hline Open well & 1.0 & 0.8 & 1.2 \\
\hline Covered well & 0.9 & 0.7 & 1.2 \\
\hline Surface water & 0.9 & 0.7 & 1.1 \\
\hline Other sources & 1.0 & 0.7 & 1.5 \\
\hline \multicolumn{4}{|l|}{ Toilet facilities(ref: flush toilet) } \\
\hline Pit toilet & 2.0 & 1.1 & 3.5 \\
\hline No toilet facilities & 2.0 & 1.1 & 3.6 \\
\hline Other facilities & 2.2 & 1.1 & 4.2 \\
\hline \multicolumn{4}{|l|}{ Energy sources (ref: electricity) } \\
\hline Paraffin & 1.1 & 0.8 & 1.6 \\
\hline Firewood & 0.3 & 0.1 & 1.0 \\
\hline Other sources & 0.5 & 0.1 & 4.3 \\
\hline Distance to health facilities & 0.9 & 0.9 & 1.0 \\
\hline
\end{tabular}

Source: computed by the authors 
Table 4 Odds ratios of child mortality with multiple predictors in Tanzania 2011-2015

\begin{tabular}{|c|c|c|c|c|c|c|c|c|c|c|c|c|}
\hline \multirow[t]{2}{*}{ Variables } & \multicolumn{3}{|c|}{ Model 1} & \multicolumn{3}{|c|}{ Model 2} & \multicolumn{3}{|c|}{ Model 3} & \multicolumn{3}{|c|}{ Model 4} \\
\hline & $B$ & Sig & $\operatorname{Exp} \beta$ & $B$ & Sig & $\operatorname{Exp} \beta$ & $B$ & Sig & $\operatorname{Exp} \beta$ & $B$ & Sig & $\operatorname{Exp} \beta$ \\
\hline \multicolumn{13}{|c|}{ Maternal education (ref: no education) } \\
\hline Primary & -0.1 & 0.8 & 0.9 & -0.6 & 0.4 & 0.6 & -0.6 & 0.5 & 0.6 & 1.2 & 0.2 & 2.2 \\
\hline Higher & -17.1 & 1.0 & 0.0 & 1.0 & 1.0 & 0.0 & 1.0 & 1.0 & 0.0 & 6.1 & 1.0 & 1.0 \\
\hline \multicolumn{13}{|c|}{ Paternal education (ref: most primary) } \\
\hline Secondary & 0.4 & 0.5 & 1.3 & 0.0 & 0.9 & 1.0 & -0.1 & 0.9 & 0.9 & -1.4 & 0.2 & 0.2 \\
\hline Higher & -15.0 & 1.0 & 0.0 & 1.0 & 1.0 & 0.0 & 1.0 & 1.0 & 0.0 & 1.0 & 1.0 & 0.0 \\
\hline \multicolumn{13}{|c|}{ Regions (ref: Dar es Salaam) } \\
\hline Other regions & 18.6 & 1.0 & 1.0 & 19.3 & 1.0 & 1.0 & 16.2 & 1.0 & 1.0 & -8.1 & 1.0 & 0.0 \\
\hline Zanzibar & 11.1 & 1.0 & 1.0 & 20.1 & 1.0 & 1.0 & 16.9 & 1.0 & 1.0 & -4.2 & 1.0 & 0.0 \\
\hline \multicolumn{13}{|c|}{ Place of residence (ref: urban) } \\
\hline Rural & 0.2 & 0.8 & 1.2 & -0.3 & 0.8 & 0.7 & 0.1 & 0.9 & 1.1 & 0.1 & 0.9 & 1.2 \\
\hline \multicolumn{13}{|c|}{ Wealth index (ref: poorer) } \\
\hline Poor & -0.3 & 0.7 & 0.8 & -0.6 & 0.5 & 0.6 & -1.1 & 0.2 & 0.4 & -2.3 & 0.1 & 0.1 \\
\hline Middle & -1.0 & 0.1 & 0.4 & -0.8 & .42 & 0.5 & -1.3 & 0.2 & 0.3 & -2.3 & 0.1 & 0.1 \\
\hline Richer & 0.2 & 0.7 & 1.3 & 0.1 & 0.9 & 1.2 & 0.0 & 0.9 & 1.0 & -0.6 & 0.7 & 0.6 \\
\hline Riches & -0.2 & 0.8 & 0.8 & -1.2 & 0.3 & 0.3 & -1.9 & 0.1 & 0.1 & -5.2 & 0.1 & 0.0 \\
\hline \multicolumn{13}{|c|}{ Occupation (ref: nonworking) } \\
\hline Working & 0.2 & 0.8 & 1.2 & 0.1 & 0.9 & 1.1 & $0-.2$ & 0.9 & 0.8 & 0.2 & .9 & 1.2 \\
\hline \multicolumn{13}{|c|}{ Age group (ref: <25) } \\
\hline $25-29$ & - & - & - & -1.8 & 0.4 & 0.2 & -1.2 & 0.6 & 0.3 & -2.2 & 0.4 & 0.1 \\
\hline $30-34$ & - & - & - & -1.4 & 0.5 & 0.3 & -1.0 & 0.6 & 0.4 & -1.9 & 0.4 & 0.1 \\
\hline $35-39$ & - & - & - & -2.2 & 0.3 & 0.1 & -1.5 & 0.5 & 0.2 & -1.9 & 0.5 & 0.1 \\
\hline $40-44$ & - & - & & -1.7 & 0.5 & 0.2 & -1.1 & 0.6 & 0.3 & -0.4 & 0.8 & 0.6 \\
\hline $45-49$ & - & - & - & -0.9 & 0.7 & 0.4 & $0-.6$ & 0.8 & 0.6 & 0.0 & 0.9 & 1.0 \\
\hline
\end{tabular}

Preceding birth intervals (ref: $<24)$

$\begin{array}{lllllllllllll}24-36 & - & - & - & -0.8 & 0.2 & 0.4 & -0.7 & 0.3 & 0.5 & -1.4 & 0.2 & 0.2 \\ 37-48 & - & - & - & 1.5 & 0.1 & 4.5 & 1.9 & 0.1 & 7.3 & 3.6 & 0.1 & 35.6 \\ 49+ & - & - & - & 0.8 & 0.4 & 2.3 & 1.2 & 0.2 & 3.5 & 0.9 & 0.5 & 2.6\end{array}$

Succeeding birth intervals (ref: <24)

$\begin{array}{lllllllllllll}24-36 & - & - & - & 0.8 & 0.3 & 2.1 & 0.8 & 0.3 & 2.2 & 1.5 & 0.1 & 4.5 \\ 37-48 & - & - & - & 0.8 & 0.4 & 2.3 & 0.8 & 0.4 & 2.3 & 1.7 & 0.2 & 5.5 \\ 49+ & - & - & - & 2.3 & 0.1 & 9.5 & 3.2 & 0.0 & 24.9 & 3.5 & 0.1 & 32.5\end{array}$

Birth parity (ref: $<3$ )

$\begin{array}{lllllllllllll}4-8 & - & - & - & 2.6 & 0.1 & 14.0 & 3.0 & 0.1 & 20.5 & 3.8 & 0.1 & 44.9 \\ 9+ & - & - & - & 1.3 & 0.5 & 3.6 & 2.0 & 0.3 & 7.7 & 16 & 0.6 & 4.9\end{array}$

Multiplicity of birth (ref: single)

$\begin{array}{ccccccccccccc}\text { 1st of multiple } & - & - & - & 1.0 & 1.0 & 0.0 & 1.0 & 1.0 & 0.0 & 1.0 & 1.0 & 0.0 \\ \text { 2nd of multiple } & - & - & - & 1.0 & 1.0 & 0.0 & 1.0 & 1.0 & 0.0 & 1.0 & 1.0 & 0.0 \\ \text { 3rd of multiple } & - & - & - & 20.9 & 0.9 & 1.0 & 20.6 & 1.0 & 1.0 & 25.6 & 1.0 & 1.0 \\ \text { Birth order (ref: <3) } & & & & & & & & & & & & \\ 4+ & - & - & - & -1.5 & 0.0 & 0.2 & -1.8 & -0.0 & 0.2 & -2.6 & 0.0 & 0.1\end{array}$

Sex of child (ref: male)

Female 
Table 4 Odds ratios of child mortality with multiple predictors in Tanzania 2011-2015 (Continued)

\begin{tabular}{|c|c|c|c|c|c|c|c|c|c|c|c|}
\hline \multicolumn{12}{|c|}{ Household head (ref: male) } \\
\hline Female & - & - & - & - & - & -0.0 & 0.9 & 0.9 & -1.7 & 0.2 & 0.2 \\
\hline \multicolumn{12}{|c|}{ Marital status (ref: single) } \\
\hline Married & - & - & 1.3 & 1.8 & 0.2 & 3.7 & 1.9 & 2.7 & 0.1 & 0.0 & 7.0 \\
\hline
\end{tabular}

Source: computed by the authors

decreasing steadily from 57 per 1000 live births in 1996; it picked up to 59 per 1000 live births in 1999 and reached its low of 31 per 1000 live births from 2003 to 2015. For life expectancy at birth, it started with a high about 55.2 years from births in 1996, and then it decreased to about 54.7 years in 1999. It became high again from 2000 (55.7 years) to 63.4 years for the period from 2003 to 2015. The researcher evaluated the aforementioned output along with a goodness of fit test.

Table 5 evaluates using the $\mathrm{H}-\mathrm{L}$ goodness of fit tests and the omnibus tests of the model coefficients; for the former, poor fit is indicated by a significance of less than 0.05 , whereas for the latter, poor fit is indicated by a significance of greater than 0.05 . The result for the H-L goodness of fit tests shows that all the variables had better fit into the model as they had significance levels of greater than 0.05 . On the other hand, the omnibus tests show variables in models 1 and 3 with the $\chi^{2}$ tests of 6.7 and 5.7, respectively, suffer poor fit ( $P$ values 0.9 and 0.2 , respectively).

\section{Discussion}

This study shows that rural children are more likely to die before reaching the age of 5 compared to their urban counterparts; the same phenomenon has also been reported in other related findings (Sathiya Susuman 2010; World Health Organization 2010). Theoretically, urban children are more likely to survive because of the amenities and opportunities found in urban areas, like proper health care facilities and access to clean water and proper sanitation (Trussell 1975; Claeson and Waldman 2000; World Health Organization 2010; Pathak and Ram 1998). On the contrary, different study findings

Table 5 Child mortality (loss /death), life expectancy in Tanzania (all deaths per 1000 live births), Tanzania 2011-2015

\begin{tabular}{lllll}
\hline Age group of women & Age $x$ & Trussel equation & CMR (4q1) & Life expectancy \\
$15-20$ & 1 & 1.01 & $<.00$ & $>75$ \\
$20-25$ & 2 & 0.07 & 0.03 & 63.4 \\
$25-30$ & 3 & 0.1 & 0.05 & 57.8 \\
$30-35$ & 5 & 0.13 & 0.05 & 56.6 \\
$35-40$ & 10 & 0.15 & 0.06 & 55.7 \\
$40-45$ & 15 & 0.18 & 0.06 & 54.7 \\
$45-50$ & 20 & 0.19 & 0.06 & 55.2 \\
Child mortality & Omnibus tests & Hosmer-Lemeshow goodness of fit tests \\
& $x^{2}$ & $P$ values & $x^{2}$ & $P$ values \\
Model 1 & 6.7 & 0.9 & 3.6 & 0.8 \\
Model 2 & 41.3 & 0 & 5.9 & 0.7 \\
Model 3 & 5.7 & 0.2 & 9.1 & 0.3 \\
Model 4 & 21.1 & 0 & 5 & 0.8 \\
\hline
\end{tabular}

Source: computed by the authors 
show a lack of health care services and facilities in both rural and urban areas. Based on study findings, a reduction in child mortality via the current development program is insufficient to achieve the MDG4 target (UNDP 2010). Therefore, Tanzania was among the 60 high-priority countries that are off target to meet the MDG4 by 2015. When risk factors of child mortality are introduced alone in the odds ratios model, maternal education was found to have a significant effect: infants born to mothers of higher education have higher odds of surviving. This is not a new phenomenon as it has been indicated in the literature that education indeed plays an important role in the survival odds of children. For example, Kerala state in India is the first largest state to have shown a notable fertility decline as a result of improvement in education, and this has attracted the attention of a number of researchers. Two factors stand out for Kerala: an early fall in mortality and a high level of education, including female education, both of which obviously favored fertility transition (Sathiya Susuman et al. 2014; UNDP 2010; Claeson et al. 2000; World Health Organization 2010; Trussell 1975). However, in Tanzania, a mother's age at first birth indicates a higher mortality for infants born to older mothers. Because many of the mothers (32\%) are illiterate, they also tend to lack knowledge of health facilities and health care service providers and knowledge about health promotion. Thus, population policy makers and healthconcerned officials want to implement a special maternal health policy (Janson 2007). The current maternal health policy suffers from implementation problems as it is not fully implemented across all regions. Present study findings similarly observe that young mothers have higher chances of infant mortality than older mothers. This might be due to an early age of marriage, and as such, mothers are not physically or mentally ready to produce a healthy child, namely due to a lack of health care awareness. Comparatively, older mothers have a lot of experience in terms of infant and child health care. Still, study results also show that the child mortality odds ratio was quite high in older mothers and this is due to a similar ignorance of health care knowledge (Morris et al. 2003; Janson 2007; UNDP 2010; Stanley 2010). The uncomfortable truth is the questionable quality of care at many of the health care facilities. Here, we noticed that birth order and distance to the nearest health facilities also showed statistically negative effects, with odds of -2.7 with less than three births. In birth order, children that belonged to the higher orders had 0.1 odds of dying. This is a major cause of child mortality. The personnel attending deliveries are very often not properly trained and, hence, not fully proficient in labor room protocols (Tanzania Demographic Health Survey 2004-2005; MoHSW 2006). Labor rooms are not always fully equipped with essential medicines, equipment, or electricity (MoHSW 2006). All of this results in the incongruity between more facilities but equally poor outcomes. Ideally, all regions are obligated to emulate women-friendly public services and are provided with fully equipped health centers with a well-trained nurse around the clock to ensure safe deliveries. However, in many African countries, health care systems are very weak. The case of Tanzania is more or less similar, but noticeable enhancements in terms of birth interval and reduced higher order of birth show a positive trend in this country. Moreover, the results suggest that ideal birth intervals should be a minimum of 36 months and greater to reduce infant, child, and under-five mortality rates. Infants of higher order are subject to a high mortality risk if the birth interval has been shortened and parity heightened. Based on the results, we could conclude 
that birth interval is one of the most important key factors to reduce child mortality. As per the study hypothesis (H1), child mortality rate is independent of all predictors of deaths that are statistically and strongly accepted.

\section{Conclusions}

What does the experience tell us about the bio-demographic factors affecting child loss in Tanzania? The study findings indicated that most children are dying due to maternal fertility behaviors, which were the significant risk factors of the odds of child mortality. A number of favorable developments have occurred that helped reduce this problem. Prominently, programs such as sleeping under insecticide-treated nets (ITNs) and vitamin A supplements have been well initiated in the country to improve the health and well-being of children. The matter of causes of child mortality entered public debates at all levels thanks to the persistent propaganda of the government program. Over time, the knowledge that child mortality is a matter of specific causes has become universal. Means of declining child mortality regulation have become available to all, including the rural, the poor, the illiterate, and the socially deprived sectors. The program played a major role here. But infant and child mortality will not continue to decline unless mothers increased the lengths of intervals between births to longer than 36 months to be beneficial. This will help mothers determine their capability and capacity to make healthy and nutritional choices and make use of available health care resources. Encouraging a longer breastfeeding period will also help produce healthy babies. Further research is needed in regional- and national-level investigations to extend an understanding of the factors affecting child mortality in Tanzania. Special fund allocation is essential. Equally, monitoring and evaluation are important to eradicate child mortality in Tanzania.

\section{Acknowledgements}

The authors would like to thank the Tanzania HIV/AIDS and Malaria Indicator Survey (2011-2012) data. The authors are grateful to the anonymous reviewers for their valuable suggestions.

\section{Authors' contributions}

SA conceived and designed the experiments. SA and HFH performed the experiments. SA analyzed the data. SA contributed the reagents/materials/analysis tools. SA and HFH wrote the paper. SA and RN made substantial contributions to the conception, acquisition, and interpretation. RN edited the article. All authors read and approved the final manuscript.

Competing interests

The authors declare that they have no competing interests.

Ethics approval and consent to participate

This study used secondary data from the Tanzania Demographic and Health Survey. Prior to using these data, an agreement was obtained from Macro International, which has allowed us to download the data on their Web site. Please note that all data are fully available without restriction.

\section{Author details}

1 Department of Statistics and Population Studies, University of the Western Cape, Bellville, Cape Town 7535, South Africa. ${ }^{2}$ Hope Centre for Children, Girls and Women, Msasani, Dar es Salaam, Tanzania. ${ }^{3}$ Department of Development Studies, International Institute for Population Sciences, Deonar, Mumbai 400088, India.

Received: 5 August 2016 Accepted: 8 September 2016

Published online: 07 November 2016

References

Ahmad, O. B., Lopez, A. D., \& Inoue, M. (2000). The decline in child mortality: A reappraisal. Bulletin of the World Health Organization, 78, 1175-1191.

Armstrong Schellenberg, J. R. M., Nathan, R., Abdulla, S., Mukasa, O., Marchant, T. J., Tanner, M., et al. (2000). Risk factors for child mortality in rural Tanzania. Tropical Medicine \& International Health, 7(6), 506-511.

Brass, W. (1968). The demography of tropical Africa. Princeton: Princeton University Press. Retrieved 2015 from https:// books.google.co.za/books?hl=en\&lr=\&id=iyvWCgAAQBAJ\&oi=fnd\&pg=PR5\&dq=Demography+of+Tropical+Africa 
+William+Brass\&ots=5WuaPvFbn8\&sig=MxvfEck193WMuPzOqfKiZe4253M\#v=onepage\&q=Demography\%20of\% 20Tropical\%20Africa\%20William\%20Brass\&f=false.

Buwembo, P. (2010). Factors associated with under-5 mortality in South Africa: trends 1997-2002 (Doctoral dissertation, University of Pretoria)

Charmarbagwala, R., Ranger, M., Waddington, H., \& White, H. (2004). The determinants of child health and nutrition: A meta-analysis. World Bank.

Claeson, M., \& Waldman, R. J. (2000). The evolution of child health programmes in developing countries. From Targeting diseases to targeting people. Bulletin of the World Health Organization, 78(10), 1234-1245.

Claeson, M., Griffin, C. C., Johnston, T. A., McLanchlan, M., Soucat, A. L. B., Wagstaff, A., \& Yazbeck, A. S. (2000). Health, Nutrition, and Population. World Bank.

Gavrilov, L. A., \& Gavrilova, N. S. (2012). Biodemography of Exceptional Longevity: Early-life and mid-life predictors of human longevity. Biodemography and Social Biology, 58(1), 14-39.

Handa, S., Koch, S., \& Wen Ng, S. (2010). Child mortality in Eastern and Southern Africa. Population Review, 49(1), Retrieved February $18^{\text {th }}, 2011$ from http://repository.up.ac.za/bitstream/handle/2263/16955/Handa_ Population\%282010\%29.pdf? sequence=1\&isAllowed=y.

Hossain, M., \& Islam, M. R. (2009). Effects of Demographic and Household variables on Infant and Child Under-5 mortality: An Application of Logistic Model. The Internet Journal of Health, 8(2), 712-727.

Janson, A. (2007). Shed some light on darkness: Will Tanzania reach the millennium development goals? Acta Paediatrica, 96(6), 781-786.

Kembo, J., \& Van Ginneken, J. K. (2009). Determinants of infant and child mortality in Zimbabwe: Results of multivariate hazard analysis. Demographic Research, 21, 367-384.

Landau, S., \& Everitt, B. S. (2004). A handbook of Statistical Analysis using SPSS. New York: Chapman and Hall/CRC Press.

Masanja, H., de Savigny, D., Smithson, P., Schellenberg, J., John, T., Mbuya, C., et al. (2008). Child survival gains in Tanzania: Analysis of data from demographic and health surveys. The Lancet, 371(9620), 1276-1283.

MoHSW. (2006). Annual Health Statistical Abstract. Dar es Salaam: Ministry of Health and Social Welfare.

MoHSW. (2008). Annual Health Statistical Abstract. Dar es Salaam: Ministry of Health and Social Welfare.

Morris, S. S., Black, R. E., \& Tomaskovic, L. (2003). Predicting the distribution of under-five deaths by cause in countries without adequate vital registration systems. International Journal of Epidemiology, 32(6), 1041.

Nattey, C. (2009). Household socio-economic status as a determinant of under five mortality at Rufiji DSS Tanzania (Doctoral dissertation).

Nure Alam, S., Nuruzzaman, H., \& Abdul, G. (2011). Differentials and Determinants of Under-five Mortality in Bangladesh. International Journal of Current Research, 3(3), 142-148.

Ojikutu, R. K. (2008). Pattern of under-five deaths in Lagos state, Nigeria. Sudanese Journal of Public Health, 3(4), 176-185.

Pathak, K. B., \& Ram, F. (1998). Techniques of Demograhic Analysis. Mumbai: Himalaya Publish House.

Rutstein, S. O. (2005). Effects of preceding birth intervals on neonatal, infant and under-five years mortality and nutritional status in developing countries: Evidence from the demographic and health surveys. International Journal of Gynecology \& Obstetrics, 89, S7-S24.

Sathiya Susuman, A. (2010). Correlates of Infant and Child mortality in Ethiopia 2005. Journal of Community and Health Sciences, 5(1), 16-25.

Sathiya Susuman, A., Siaka Lougue, \& Madhusudana, B. (2014). Female literacy, fertility decline and life expectancy in Kerala, India: an analysis from census of India 2011. Journal of Asian and African Studies. doi:10.1177/0021909614541087. (ISSN: 0021-9096), http://jas.sagepub.com/content/early/2014/07/11/0021909614541087.abstract

Shipanga, I. (2007). Demographic and Socio-Economic Determinants Associated with Child Mortality Decline in Namibia: Analysis of Two DHS Surveys (Doctoral dissertation, University of the Western Cape)

Stanley, R. (2010). Trends in Child Survival in Sierra Leone, 1961 - 2008. University of Oxford. Retrieved http://www.csae. ox.ac.uk/conferences/2010-EDiA/papers/436-Stanley.pdf.

Tanzania Demographic Health Survey 2004-2005. Retrieved March 2010 from http://dhsprogram.com/pubs/pdf/FR173/ FR173-TZ04-05.pdf

Tanzania HIV/AIDS Malaria Indicator Survey 2011-2012. Retrieved 2011 from https://dhsprogram.com/pubs/pdf/AlS11/AIS11.pdf

Tanzania Millennium Development Goals 2010. Country Report. Retrieved January 2011 from http://www.tz.undp.org/ content/dam/tanzania/Tanzania\%20MDG\%20Report\%202010.pdf

Trussell, T. J. (1975). A re-estimation of the multiplying factors for the Brass technique for determining childhood survivorship rates. Population Studies, 29(1), 97-107.

UNDP. (2010). Millennium Development Goal 4 publication. Retrieved February $5^{\text {th }}, 2011$ from http://www.un.org/ millenniumgoals/pdf/MDG\%20Report\%202010\%20En\%20r15\%20-low\%20res\%2020100615\%20-pdf

Whiting, D. R., Setel, P. W., Chandramohan, D., Wolfson, L. J., Hemed, Y., \& Lopez, A. D. (2006). Estimating cause-specific mortality from community-and facility-based data sources in the united republic of Tanzania: Options and implications for mortality burden estimates. Bulletin of the World Health Organization, 84(12), 940-948.

World Health Organization. (2010). MDG 4 Reduce child mortality. World Health Organization. Retrieved January $30^{\text {th }}$, 2011 from http://www.who.int/topics/millennium_development_goals/child_mortality 